\title{
Chitosan Isolated from Horseshoe Crab Tachypleus gigas from the Malay Peninsula
}

\section{ZALEHA KASSIM ${ }^{1 *}$, WAN NURUL AKMAL WAN MURNI ${ }^{1}$, MOHD RAZALI MD RAZAK', WAN SYAZZAWANI WAN ${ }^{1}$ OMAR and SAKINAH BEGUM ADAM ${ }^{2}$}

\author{
${ }^{1}$ Kulliyyah of Science, International Islamic University Malaysia, Jalan Sultan Ahmad Shah, \\ Indera Mahkota, 25200 Kuantan, Pahang, Malaysia. \\ ${ }^{2}$ Faculty of Health \& Life Sciences, Management \& Science University, Seksyen 13, \\ 40150 Shah Alam, Selangor, Malaysia. \\ ${ }^{*}$ Corresponding author E-mail: drzack@iium.edu.my
}

http://dx.doi.org/10.13005/ojc/340242

(Received: November 24, 2017; Accepted: February 01, 2018)

\section{ABSTRACT}

Chitosan that was isolated from horseshoe crabs, Tachypleus gigas, for this study were from estuary area in Balok Pahang (East coast) and Muar Johor (West coast) of the Malay Peninsula. The isolation of chitosan was carried out by chemical processes involving deproteinization, demineralization and deacetylation. Physicochemical properties and antibacterial activity were analysed to determine its potential commercialization. The degree of deacetylation (DD) was higher for samples from Balok than Muar (42.4\% and $35.2 \%$ respectively), but lesser than the commercial grade. There was no significant difference $(p>0.05)$ in the physicochemical properties but obviously they had lesser moist $(1.11 \pm 0.22-1.25 \pm 0.13 \%)$, higher ash content $(1.99 \pm 0.06-2.37 \pm 0.07 \%)$, and low in its solubility $(58.00 \pm 9.63-61.70 \pm 1.35 \%)$ as well as viscosity $(52.52 \pm 5.38-64.37 \pm 4.73 \mathrm{cP})$ if compared with commercial chitosan. Chitosan from both field sites also showed great antibacterial activities which concentration dependent against Staphylococcus aureus and Eschericia coli.

Keywords: Chitin and chitosan, Horseshoe crab, Physicochemical and Antibacterial properties.

\section{INTRODUCTION}

Horseshoe crab, a chelicerate arthropod, is among the world's oldest and most fascinating creatures. It has survived from the ancient time until now and thus, it is called as the living fossil. In Malaysia, there are three species which are commonly found in the coastal water; Tachypleus gigas, in the estuary area, Carcinoscopius rotundicauda, and the biggest horseshoe crab strictly found in Sabah water, Tachypleus tridentatus. The natural land barrier of the Malay Peninsula has contributed to the genetically differentiated population from those of 
the Indian Ocean and those of the South China $\mathrm{Sea}^{1}$, at least for T. gigas. Horseshoe crab also has extraordinary defense mechanism due to its blood property. Nowadays, horseshoe crab has been recognized for its contribution in medicine and pharmaceutical science. Its carapace contains a compound called chitin and essentially, chitins as well as its derivative chitosan have played big roles in various fields of applications ${ }^{2}$.

Chitin is the second most important and ubiquitous natural polysaccharide after cellulose and it can be extracted from the shell of horseshoe crabs, marine invertebrates, insects, fungi and yeast. It has a polymeric substance derived from crustaceous shell which is a composed of $\beta(1 \rightarrow 4)$ linked 2-acetamido-2-deoxy- $\beta$-D-glucose. This polymeric substance is an acetamido group $\left(-\mathrm{NHCOCH}_{3}\right)$ instead of hydroxyl group at C-2. Chitin functions like cellulose as structural polysaccharide and its derivative chitosan has a linear polymer of $\beta(1 \rightarrow 4)$-linked 2-amino-2-deoxy- $\beta$-D-glucopyranos ${ }^{3}$. Chitosan is a fiber-like substance derived from chitin by $\mathrm{N}$-deacetylation and comprised copolymer of $\mathrm{N}$-acetylglucosamine and glucosamine. It is obtained from chitin by deacetylation; a process where acetyl group is removed. The degree of deacetylation determined the chitosan produced from chitin. The removal of enough acetyl group $\left(\mathrm{CH}_{3}-\mathrm{CO}\right)$ from chitin has resulted the chitin molecule and its derivative, chitosan, to be soluble in most diluted acid. The acetyl content of the polymer has become the actual variation between chitin and chitosan.

Chitin and chitosan as biopolymer have many functions and utilizations. Nonetheless, there are still restrictions in the product properties due to certain processes ${ }^{4}$. The standard procedure of isolation involved of three basic steps; deproteinization (protein separation), demineralization (calcium carbonate and calcium phosphate separation) and deacetylation (removal of acetyl group) which is for the subsequent conversion of chitin to chitosan. The conversion of chitosan where some or all acetyl groups are removed from chitin is generally achieved by treatment with concentrated sodium hydroxide solution (40-50\%) at $100 \stackrel{\circ}{\circ} \mathrm{C}$ or higher temperature ${ }^{5}$. As reported before $^{6}$, physicochemical characteristics of chitosan affects its functional properties such as dye binding capacity, water binding capacity, fat binding capacity, and emulsifying capacity, which also differ depending on the crustacean species and its preparation methods.

Antimicrobial resistance is a threat to mankind because most of the infection causing bacteria has become multidrug resistant ${ }^{7}$. The antibacterial activities of chitosan have been demonstrated against Gram-positive and Gram-negative bacteria by many researchers $8,9,10$. The polycationic nature of chitosan is prerequisite for antimicrobial activity. Eventually, the interaction between the positively charged $\mathrm{NH} 3+$ groups and the negatively charged microbial cell surface contribute to the leakage of protein and other intracellular components of the microbial cells, ultimately resulting in the impairment of vital bacteria activities ${ }^{11,12,13}$.

Considering the possibility of genetic difference due to different marine environment ${ }^{1}$, physicochemical and biological properties of chitosan from those horseshoe crabs could also be different. Hence, the general objective for this research was to study the physicochemical properties and antibacterial activities of chitosan prepared from horseshoe crab carapace obtained from different coastal landing area of the Malay Peninsula. The sampling site was at Balok in the east coast and Muar in the west coast of the Malay Peninsula. Balok received sea water from the South China Sea, while Muar from the Straits of Malacca.

\section{METHODOLOGY}

\section{Sample Collection}

The amount of 40 live horseshoe crabs (Tacypleus gigas) from coastal area of Balok, Pahang (East coast) and coast area of Muar, Johor (West coast) were collected from those caught by fishermen. The horseshoe crabs were then brought to oceanography laboratory and kept in the freezer.

\section{Isolation of Chitin and Chitosan}

The carapaces were removed from the body of the horseshoe crabs. The loose tissue and the muscle on the carapaces were scraped free and washed thoroughly with tap water. Then, the 
carapaces were completely dried using Memmert oven at $60^{\circ} \mathrm{C}$ overnight. The dried carapaces were then weighed and recorded. The dried carapaces were cut into smaller size before grinding using SHARP commercial glass blender. The ground horseshoe crab carapaces were sieved using a 250 micrometer sieve mesh and sieve shaker to get a uniform particle size. Then, the carapaces powder was weighed and kept in the Schott bottle before being extracted. Deproteinization was carried out ${ }^{14}$, followed by demineralization, and then deacetylation ${ }^{15}$.

\section{Characterization of Chitosan from Horseshoe Crab Carapace}

Chitosan samples were prepared in a form of thin disk, which was a mixture of $\mathrm{KBr}$ and chitosan's powder with the ratio 3:1. The sample mixture was thoroughly mixed, ground into fine particles, and then pressed in order to form homogenous thin sample disc. Next, the disc was kept in a desiccator for $16 \mathrm{~h}$. before placing the $\mathrm{KBr}$ disc in a sealed plate for scanning. The spectra of the chitosan discs were obtained by using FT-IR with the frequency range of $4000-400 \mathrm{~cm}^{-1}{ }^{16}$. The functional groups of the chitosan samples were confirmed by comparing the spectra obtained with the spectra obtained in the reference study ${ }^{17}$.

The deacetylation degree (DD) of the chitosan samples were calculated using the computational equation baseline ${ }^{18}$ as below:

$\mathrm{DD}=100-\left(\frac{\mathrm{A}_{\mathrm{t} 655}}{\mathrm{~A}_{9450}}\right) \times \frac{100}{1.33}$

$A_{1655}$ refers to the absorbance at $1655 \mathrm{~cm}^{-1}$ of the amide-I band as a measure of the $\mathrm{N}$-acetyl group content, while $\mathrm{A}_{3450}$ refers to the absorbance at $3450 \mathrm{~cm}^{-1}$ of the hydroxyl band as an internal standard to correct for disc thickness or differences in chitosan concentration powder form. The factor '1.33' denoted the value of the ratio of $A_{1655} / A_{3450}$ for fully $\mathrm{N}$-acetylated chitosan.

The moisture content of horseshoe crab chitosan from Balok and Muar were determined using moisture analyzer (PRESICA XM 50). The ash content was calculated by using the formula below
Ash content $(\%)=\frac{\text { Weight of ash }}{\text { Weight of sample }} \times 100 \%$

For solubility, $0.3 \mathrm{~g}$ of horseshoe crab chitosan was weighed and kept in a pre-weighted centrifuge tube in triplicates. The mixtures of chitosan and acetic acid were centrifuged (Universal 320R, Zentrifugen) at 9,000 rpm for 15 minutes. The supernatant liquid was removed again and the residue was dried at $60{ }^{\circ} \mathrm{C}$ for $24 \mathrm{~h}{ }^{17}$. Finally, the dried particles were weighed and the percentage of solubility was calculated with the given formula.

Solubility $(\%)=\frac{\text { (Initial weight-Final weight) }}{\text { Chitosan }} \times 100 \%$

The $1 \%(\mathrm{w} / \mathrm{v})$ of chitosan solutions was prepared in $1 \%$ acetic acid to analyse its viscosity. Then, the viscosity was measured by using viscometer (Vibro SV-10). The result appeared when it became constant and was recorded in $\mathrm{mPa}$.s (1cP $=1 \mathrm{mPa} . \mathrm{s}$ ).

\section{Antibacterial Activity of Horseshoe Crab Chitosan by Disc Diffusion Method}

The disc diffusion method was used to test the antibacterial activity of horseshoe crab chitosan from Balok and Muar. The bacteria strains used for this antimicrobial test were Staphylococcus aureus and Escherichia coli. Müeller-Hinton agar medium was poured into petri dishes and allowed to solidify. A total of 100 microLiter diluted inoculum of bacteria strains was spread evenly on the agar plates by using hockey stick spreader. The sterilized paper discs were impregnated with 100 microLiter of diluted chitosan solution ( $1 \%, 0.5 \%, 0.4 \%, 0.3 \%$, $0.2 \%, 0.1 \%(\mathrm{w} / \mathrm{v}))$ and placed on surface of the agar mediums with $1 \%$ solution of acetic acid as negative control and streptomycin as positive control. Then the agar plates were incubated at $37^{\circ} \mathrm{C}$ for 24 hours.

\section{RESULTS AND DISCUSSION}

\section{Yield of Chitosan from Horseshoe Crab Carapace}

The chitosan yield in this study ranged from 12.7-15.0\% depending on the source of horseshoe $\mathrm{crab}^{19}$ and method used ${ }^{20}$. The yields of chitosan were comparable for both coastal areas (Table 1) but lower than the percentage yield 
reported before ${ }^{14}$. Excessive removal of acetyl group from the polymer during deacetylation could cause loss of sample weight or could be due to the loss of chitosan particles during filtering and washing ${ }^{21}$. On the other hand, chitosan yield might be depending on the length and alkaline and acid concentration used during deproteinization and demineralization ${ }^{22}$.

Chitosan Structure Analysis and Degree of

Table 1: Percentage yield of chitosan isolated from horseshoe crab carapace obtained from Balok and Muar in the Malay Peninsula

\begin{tabular}{lcc}
\hline Sources & $\begin{array}{c}\text { Percentage } \\
\text { Yield (\%) }\end{array}$ & $\begin{array}{c}\text { Yield } \\
(\% \text { per g) }\end{array}$ \\
\hline Balok (380 g) & 12.7 & 0.033 \\
Muar (500 g) & 15.0 & 0.030 \\
\hline
\end{tabular}

\section{Deacetylation}

The chitosan obtained from Balok and Muar were analyzed using FT-IR in order to determine its functional groups and degree of deacetylation. The absorption band ranging from 3444-3442 $\mathrm{cm}^{-1}$ were related to $v(\mathrm{~N}-\mathrm{H})$ in $v\left(\mathrm{NH}_{2}\right)$ assoc. in primary amines or $v(\mathrm{OH})$. Meanwhile, the absorption bands that ranged from $1661-1628 \mathrm{~cm}^{-1}$ contributed to amide I band, while amide II band were located in between 1566-1562 $\mathrm{cm}^{-1}$. To highlight, the larger intensity band in the region 1566-1562 $\mathrm{cm}^{-1}$ compared to the region $1661-1628 \mathrm{~cm}^{-1}$ suggested the effectiveness of deacetylation which also indicated the presence of $\mathrm{NH}_{2}$ groups. The presence of $\mathrm{CH}_{3}, \mathrm{CH}_{2}$ and $\mathrm{CH}$ groups, the primary and secondary $\mathrm{OH}$ groups that attached to the pyranose ring and also the presence of oxygen atoms in ether (C-O-C) groups could be confirmed by the absorption bands in the region $1420-800 \mathrm{~cm}^{-1}$.

From the FT-IR spectra in Fig. 1, the degrees of deacetylation for both chitosan were calculated in order to obtain the percentages of chitin which had been converted into chitosan. From Table 2, the chitosan from Balok showed higher degree of deacetylation compared to the chitosan from Muar with $42.4 \%$ and $35.2 \%$ respectively. The degree of deacetylation observed for both chitosan was relatively low (80\%) compared to the previous study ${ }^{5}$. The low degree of deacetylation obtained in this study was perhaps due to its source and method of purification ${ }^{14}$. Furthermore, the acetyl groups bound in chitin that was hard to be removed also caused incomplete degree of deacetylation. Higher concentration of $\mathrm{NaOH}$ up to $60 \%$ and high temperature were therefore used in order to increase degree of deacetylation ${ }^{23}$. Processing condition was found to also increase degree of deacetylation ${ }^{24}$.

Moisture Content

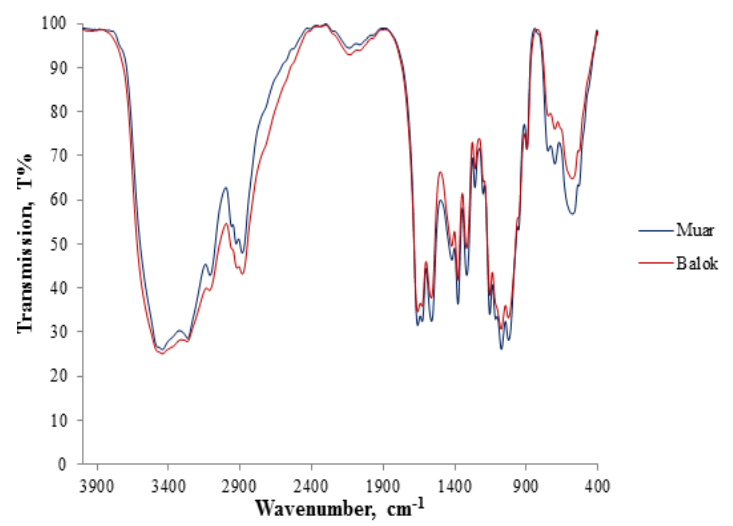

Fig. 1. FT-IR spectra of chitosan isolated from horseshoe crab obtained from Muar and Balok in the Malay Peninsula

The moisture in horseshoe crab chitosan samples was $1.11 \%$ and $1.25 \%$ for Balok and Muar respectively. Both chitosan were comparable and had less moisture content compared to commercial chitosan. Commercial chitosan contains moisture of less than $10 \%{ }^{25}, 26$. This indicated that both

Table 2: Deacetylation degree and Physicochemical Properties of Horseshoe Crab Chitosan

\begin{tabular}{lccccc}
\hline Chitosan & $\begin{array}{c}\text { Deacetylation } \\
\text { Degree }(\%)\end{array}$ & $\begin{array}{c}\text { Moisture } \\
(\%)\end{array}$ & $\begin{array}{c}\text { Ash } \\
(\%)\end{array}$ & $\begin{array}{c}\text { Solubility } \\
(\%)\end{array}$ & $\begin{array}{c}\text { Viscosity } \\
(\mathrm{cP})\end{array}$ \\
\hline Balok & 42.4 & $1.11 \pm 0.226$ & $1.99 \pm 0.061$ & $61.7 \pm 1.347$ & $64.37 \pm 4.733$ \\
Muar & 35.2 & $1.25 \pm 0.127$ & $2.37 \pm 0.074$ & $58.0 \pm 9.626$ & $52.52 \pm 5.377$ \\
Commercial & 58.4 & $3.50 \pm 0.070$ & $1.80 \pm 0.050$ & $87.8 \pm 2.340$ & $384.5 \pm 24.08$ \\
SIGMA91 & & & & & \\
\hline
\end{tabular}


chitosan from Balok and Muar were in good levels of moisture.

\section{Ash Content}

Ash content of a high and good quality grade of chitosan should be lower than $1 \%{ }^{5}$. Nonetheless, Table 2 shows that both chitosan had more than $1 \%$ of ash content (Balok had $1.99 \%$; Muar had $2.37 \%$ ). The higher ash content was due to high mineral content left in chitosan which could be due to poor demineralization process when using low concentration of $\mathrm{HCl}$. Low concentration of $\mathrm{HCl}$ used in the process of demineralization reduced the effectiveness in removing all minerals from chitin, thus produced higher ash content ${ }^{27}$.

\section{Solubility}

From Table 2, the solubility of chitosan obtained in this study was $61.7 \%$ and $58 \%$ for Balok and Muar's horseshoe crab respectively. Both values were comparable. However, when the solubility of chitosan samples were compared to commercial grade, the solubility of both chitosan was considered low. In previous study, the chitosan extracted from other crustaceans such as crab, crawfish and prawn had solubility ranged from 90-99\%. The lower solubility values of chitosan samples were due to the lower degree of deacetylation. The solubility of chitosan will proportionally increase with the increasing degree of deacetylation ${ }^{21}$. Conventional method of deacetylation might affect the production if compared with modern method such as microwave heating method ${ }^{28}$. Incomplete elimination of protein and acetyl group can also lower its solubility value. Since solubility of chitosan depends on withdrawal of acetyl group from chitin, the lower degree of deacetylation and the presence of protein impurities left in the sample during the process of analysis could cause lower solubility ${ }^{16}$.

\section{Viscosity}

Viscosity of chitosan varies within the range of 60 to $5110 \mathrm{cP}$ depending on the species ${ }^{29}$. In this study, the viscosity of horseshoe crab chitosan was $64.37 \mathrm{cP}$ for Balok and $52.52 \mathrm{cP}$ for Muar which were within the expected range. However, these viscosity values were considered lower when they were compared to the commercial chitosan which was $384.5 \mathrm{cP}$. This may be due to the lower degree of deacetylation, which might be caused by the increasing time during demineralization ${ }^{30}$. Some ash residual during the process could also contribute to lowering the viscosity condition as found in the extraction of chitosan from shrimp carapace ${ }^{31}$. Recent report ${ }^{32}$ noted that low viscous chitosan is useful in the industrial handling and application since higher molecular weight chitosan may not be desirable for industrial application.

\section{Antibacterial Activity of Horseshoe Crab Chitosan}

The results of antibacterial inhibition zone and minimum inhibitory concentration of horseshoe crab chitosan using disc diffusion are presented in the Table 3. Chitosan from both areas showed positive results inhibiting the growth of the bacteria. At concentration of $0.5 \%$ chitosan, all bacteria have been inhibited. However, the chitosan from Muar exhibited smaller inhibition zone compared to chitosan from Balok. This may be due to less solubility of the chitosan from Muar. A previous report noted on the absence of findings which lead to any conclusive data as to whether the chitosan has higher activity on gram-positive or on gram-negative bacteria ${ }^{33}$.

S. aureus showed greater inhibition zone compared to $E$. coli in the present study. Chitosan in the previous studies also showed better inhibition to the growth of Gram positive-than Gram negative-bacteria ${ }^{34,35}$. Chitosan extracted from

Table 3: Diameter of inhibition and minimum inhibition concentration (MIC)

\begin{tabular}{|c|c|c|c|c|c|c|c|c|}
\hline \multirow[t]{3}{*}{ Bacteria strain } & \multirow[t]{3}{*}{ Chitosan } & \multicolumn{6}{|c|}{ Concentration of Chitosan in Acetic Acid } & \multirow[t]{3}{*}{ MIC } \\
\hline & & $1 \%$ & $0.50 \%$ & $0.40 \%$ & $0.30 \%$ & $0.20 \%$ & $0.10 \%$ & \\
\hline & & \multicolumn{6}{|c|}{ Diameter of inhibition, (mm) } & \\
\hline \multirow[t]{2}{*}{ S. aureus } & Balok & 8 & 7.5 & 7 & 0 & 0 & 0 & $0.40 \%$ \\
\hline & Muar & 8 & 6.5 & 6.5 & 0 & 0 & 0 & $0.40 \%$ \\
\hline \multirow[t]{2}{*}{ E. coli } & Balok & 8 & 6.5 & 0 & 0 & 0 & 0 & $0.50 \%$ \\
\hline & Muar & 7 & 6.5 & 0 & 0 & 0 & 0 & $0.50 \%$ \\
\hline
\end{tabular}


horseshoe crabs was found to have good antibacterial properties as shown by the experiment. At the same time, its physicochemical properties gave a promising quality to meet the commercial grade. This is very much depending on the condition of the chitosan preparation ${ }^{2}$. It could be a great alternative to produce chitosan from horseshoe crab instead of fungi, insect and others as it can be a way to manage waste.

\section{CONCLUSION}

The chitin and chitosan isolated from horseshoe crabs obtained from Balok and Muar in the Malay Peninsula showed insignificant difference in their physicochemical and antibacterial properties. Improvement of isolation methods could further improve the degree of deacytelation, thus enhance their commercial properties.

\section{ACKNOWLEDGEMENT}

This study was funded by The Ministry of Higher Education Malaysia under the Fundamental Research Grant Scheme (FRGS 2015-2017), FRGS15-199-0440.

\section{REFERENCES}

1. Liew, P.L.; Ng, W.L.; Tan, S.G. Mar. Biol. Res., 2015, 5, 1-8.

2. Islem, Y.; Marguerite, R. Mar. Drugs., 2015, 13, 1133 - 1174.

3. Dutta, P.K.; Dutta, J.; Triphati, V.S. J. Sci. Ind. Res., 2014, 63, 20 - 31.

4. Pillai, C.K.S.; Paul, W.; Sharma, C.P. Prog. Polym. Sci., 2009, 34(7), 641 - 678.

5. No, H.K.; Meyers, S.P. J. Aquat. Food. Prod. T., 1995, 4(2), 27 - 52.

6. Cho, Y.I.; No, H.K.; Meyers, S.P. J. Agr. Food. Chem., 1998, 46(9), 3839 - 3843

7. Saeed, S.; Naim, A.; Tariq, P. Int. J. Biol. Biotech., 2007, 4(1), 71 - 74.

8. Tsai, G.J.; Su, W.H. J. Food. Prot., 1999, 62, $239-243$.

9. No, H.K.; Park, N.Y.; Lee, S.H.; Meyers, S.P. Int. J. Food. Microbiol., 2002, 74, 65 - 72.

10. Chhabra, P.; Huang, Y.W.; Frank, J.F.; Chmielewski, R.; G ates, K. J. Food. Prot., 2006, 69, 1600 - 1604

11. Muzzarelli, R.; Tarsi, R.; Fillippini, O.; Giovanetti, E.; Biagini, G.; Varaldo, P.E. Antimicro. Ag. Chemotherap., 1990, 34, 2019 - 2023.

12. Helander, I.M.; Nurmiaho-Lassila, E.L.; Ahvenainen, R.; Rhoades, J.; Roller, S. J. Food Microbiol., 2001, 71, 235 - 244.

13. Kong, M.; Chen, X.G.; Xing, K.; Park, H.J. Int. J. Food. Microbiol., 2010, 144, 51 - 63.

14. No, H.K.; Meyers, S.P. J. Agr. Food. Chem., 1989, 37(3), 580 - 583.

15. No, H.K.; Park, N.Y.; Meyers, S.P. J. Agr. Food. Chem. 2003., 51(26), 7659 - 7663.

16. Nessa, F.; Masum, S.M.; Asduzzaman, M.; Roy, S.K.; Hossain, M.M.; Jahan, M.S. Bangl. J. Sci. Ind. Res., 2010, 45(4), 323 - 330.

17. Kumaria, S.; Rath, P.K. Procedia Materials Science 6, 3rd International Conference on Materials Processing and Characterisation (ICMPC 2014)., 2014, 482 - 488.

18. Domszy, J.G.; Roberts, G.A.F. Macromol.
Chem. Phys., 1985, 186, 1671 - 1677.

19. Simone, L.L.R.; Rogerio, S.S.; Alexandra, P.P.; João, P.M.; Tiago, F.M.; Rui, H.S.; Reis, L. Eur. Polym. J., 2017, 95, $232-240$.

20. Khan, T.A.; Peh, K.K.; Ch'ng, H.S. J. Pharm. Pharm. Sci., 2002, 5(3), 205 - 225.

21. Hossain, M.S.; Iqbal, A. J. Bangl. Agr. Uni., 2014, 12(1), 153 - 160.

22. Samar, M.M.;El-Kalyoubi, M.H.;Khalaf, M.M.;Abd El-Razik, M.M. Ann. Agr. Sci., 2013, 58, 33 - 41.

23. Horgano, H.; Djaeni, M. Journal of Coastal Development., 2003, 7(1), 31 - 37.

24. Yuan, Y.; Chesnutt, B.M.; Haggard, W.O.; Bumgardner, J.D. Materials., 2011, 4(8), $1399-1416$.

25. Li, Q.; Dunn, E.T.; Grandmaison. E.W.; Goosen, M.F.A. J. Bioact. Compat. Pol., 1992, 7, $370-397$.

26. Alishahi, A.; Mirvaghefi, A.; Tehrani, M.R.; Farahmand, H.; Shojaosadati, S.A.; Dorkoosh. F.A.; Elsabee, M.Z. J. Polym. Environ., 2011, $19,776-783$.

27. Sarbon, N.M.; Sandanamsamy, S.; Kamaruzaman, S.F.S.; Ahmad, F. J. Food. Sci. Technol., 2015, 52(7), 4266 - 4275.

28. AlSagheer, F.A.; Al-Sughayer, M.A.; Muslim, S.; Elsabee, M.Z. Carbohyd. Polym., 2009, 77(2), $410-419$.

29. Bough,W.A.;Salter,W.L.;Wu, A.C.M.;Perkins, B.E. Biotechnol. Bioeng., 1978, 20(12), 1931 - 1943.

30. Moorjani, M.N.; Achutha, V.; Khasim, D.I. J. Food. Sci. Technol., 1975, 12, 187 - 189.

31. El-Syed, S.L.; El-Baghaty, A.A.E. Assiut. J. Agric. Sci., 2011, 42(5), 17 - 30.

32. Al-Hassan, A.A. Civ. Environ. Res., 2016, 8(3). $117-121$

33. Goy, R.C.; de Britto, D.; Assis, O.B.G. Polímeros: Ciência e Tecnologia., 2009, 19(3), 241 - 247.

34. No, H.K.; Park, N.Y.; Lee, S.H.; Meyers, S.P. Int. J. Food. Microbiol., 2002. 74(1-2), $65-72$.

35. Takahashi, T.; Imai, M.; Suzuki, I.; Sawai, J. Biochem. Eng. J., 2008, 4O(3), 485 - 491. 